\title{
Validating homicide rates in the Western Cape Province, South Africa: Findings from the 2009 Injury Mortality Survey
}

\author{
M Prinsloo, ${ }^{1} \mathrm{MPH} ; \mathbf{R}$ Matzopoulos, ${ }^{1,2} \mathrm{PhD}$; R Laubscher, ${ }^{3}$ BComm (Maths); J Myers, ${ }^{2} \mathrm{PhD} ;$ D Bradshaw, ${ }^{1}$ DPhil \\ ${ }^{1}$ Burden of Disease Research Unit, South African Medical Research Council, Cape Town, South Africa \\ ${ }^{2}$ School of Public Health and Family Medicine, Faculty of Health Sciences, University of Cape Town, South Africa \\ ${ }^{3}$ Biostatistics Unit, South African Medical Research Council, Cape Town, South Africa
}

Corresponding author: M Prinsloo (megan.prinsloo@mrc.ac.za)

\begin{abstract}
Background. The Western Cape Province had the highest homicide rates in South Africa during the early 2000s. South African Police Service (SAPS) data suggested a significant decline in homicide rates in the Western Cape since 2007. It ranked second highest to the Eastern Cape Province until 2013 and ranked highest again at 52.1/100 000 in 2015. A recent national injury mortality survey offers an alternative data source to assess whether the decline in homicide rates in the Western Cape was real.

Methods. A retrospective record review of autopsies was conducted from 45 state mortuaries in eight provinces for 2009. In addition, mortality data for the Western Cape were sourced from the Provincial Injury Mortality Surveillance System. Age-standardised mortality rates and crude homicide rates per 100000 population were calculated to compare with the SAPS crude rates.

Results. Our study found that the Western Cape had a provincial age-standardised homicide rate of 40.1/100 000 in 2009 and ranked fourth highest among the nine provinces. The crude homicide rate of $43 / 100000$ for the Western Cape was similar to the SAPS provincial homicide rate of 42.4/100 000. The Northern Cape Province was the only notable exception to our provincial homicide rate ranking comparison with the SAPS for 2009.

Conclusions. The Western Cape is fortunate to have alternative data sources to monitor trends in homicides over time. The latest release of the 2014/2015 SAPS crime statistics should be assessed in a similar manner, with a more recent data source, to validate accuracy of the provincial rates on a regular basis.
\end{abstract}

S Afr Med J 2016;106(2):193-195. DOI:10.7196/SAMJ.2016.v106i2.10211

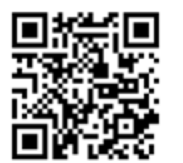

More than a decade ago, the Western Cape Province of South Africa (SA) was considered to have the highest homicide rate in the country. The first National Burden of Disease study for $2000^{[1]}$ estimated that the age-standardised homicide rate in the Western Cape was highest at 74/100 000 population, compared with a national average of 67/100 000. High homicide rates in the Western Cape were also noted in the five-city trend analysis from 2001 to $2005,{ }^{[2]}$ which indicated that Cape Town had the highest average homicide rate compared with selected cities in other provinces. Analysis of South African Police Service (SAPS) data for 2002/2003 indicated that the homicide rate of $85 / 100000$ in the province was approximately 1.8 times the national average, ${ }^{[3]}$ albeit based on crude rates that did not account for provincial differences in the age profile.

SAPS data suggest that there has been a significant decline in homicide rates in the Western Cape relative to other provinces since 2007 (Fig. 1). A 5-year period of relatively constant rates followed, during which it ranked second to the Eastern Cape Province, although it started to increase from 2013 and ranked highest once again at 52.1/100 000 for the 2014/2015 financial year. ${ }^{[4,5]}$

The importance of the decline in 2007 may have been missed amid the annual media maelstrom that follows the release of police crime statistics, or perhaps because crime statistics in SA - even homicide statistics, which in the rest of the world are the most widely used measure to compare the extent of interpersonal violence across countries, cities and regions $s^{[6]}-$ are considered inaccurate..$^{[7]}$

A recent study of injury mortality, undertaken as part of the second National Burden of Disease study, recorded 13\% more homicides than the police in $2009^{[8]}$ and offers an alternative data source to assess whether the decline in the homicide rates in the Western Cape was real. It also provides information about homicide rates in metropolitan (metro) areas compared with non-metropolitan (non-metro) areas.

\section{Methods}

We conducted a retrospective record review of autopsies from 45 state mortuaries in eight provinces for 2009. Mortuaries were selected by multistage cluster sampling and stratified by metro (comprising the metropolitan municipalities of the City of Cape Town, the City of Johannesburg, the City of Tshwane, Ekurhuleni, eThekwini and Nelson Mandela Bay) and non-metro area, as well as mortuary size, which varied from small (up to 500 bodies) to large mortuaries ( $>1500$ bodies). Full details of the sampling strategy and methodology are available in Matzopoulos et al.$^{[8]}$ Mortality data were sourced from the Western Cape's Provincial Injury Mortality Surveillance System ${ }^{[9]}$ to complete the national sample.

Fieldworkers were trained to review postmortem folders and to capture the required information on a mobile phone loaded with custom-designed software. ${ }^{[10]}$ Death records were first assessed for natural, non-natural or undetermined causes, after which information on age, gender, population group, date of death, apparent manner of death and external cause of death, consistent with the 10th revision of the International Statistical Classification of Diseases and Related Health Problems, ${ }^{[11]}$ was captured. Age-standardised mortality rates per 100000 population were calculated for homicide, suicide, unintentional injuries, transport and deaths where the intent was undetermined. ${ }^{[8]}$ 


\section{Results}

The Western Cape had a provincial agestandardised homicide rate of 40.1/100 000 population in 2009, ranking fourth highest among the nine provinces and close to the national average of $38.4 / 100000$ (Table 1). There was a marginal difference between the metro and non-metro areas in the Western Cape. The Eastern Cape had the highest homicide rate at $57.9 / 100000$, which was 1.5 times the national average. KwaZulu-Natal Province (KZN) had the highest metro homicide rate $(72.3 / 100000)$, considerably higher than the rate for the province's non-metro area of 37.9/100 000 .

There was not much difference between the age-standardised rates and crude rates in our study. The crude homicide rate of 43/100 000 for the Western Cape was similar to the SAPS provincial homicide rate of $42.4 / 100000$ for the 2009/2010 financial years (Fig. 1). Our analysis also confirms the SAPS finding that the Eastern Cape had the highest homicide rate. However, there are two exceptions in the top four ranking comparison of our study with the SAPS for 2009 - KZN ranked third highest for the SAPS, while the Northern Cape Province was the least consistent with our findings, our study's homicide rate being 1.6 times higher than that of the SAPS.

\section{Discussion}

The ranking of provincial homicide rates in our study was very similar to the SAPS crime statistics for 2009, with the notable exception of the Northern Cape. This finding is consistent with the reported decrease in Western Cape homicide rates.
The reasons for this decrease are unclear. The province's holistic approach to violence prevention, which supports evidence-based approaches for violence prevention and a review and consultation process aimed at aligning existing performance priorities and deliverables across departments, has received some international recognition, but was only formally adopted in 2013. ${ }^{[12]}$ Nationally, the significant decrease in homicides from 2000 has been attributed to the decline in firearm homicide corresponding with the implementation of the Firearms Control Act (No. 60 of 2000). Matzopoulos et al. ${ }^{[2]}$ reported a consistent year-on-year decline in firearm homicide rates in five major cities from 2001 to 2005. Cape Town's decline in firearm homicide rates from 34.4 to $20.9 / 100000$ from 2001 to 2005 was sharper than Durban's decline of 38.2 - 28.3 for the same period. ${ }^{[13]}$ The 2009 Injury Mortality Survey found that this decline was sustained for the Western Cape, with firearms accounting for $22 \%$ of homicides compared with $42 \%$ in $\mathrm{KZN}^{[14]}$ A study conducted in rural areas of KZN reported firearms to account for an average of $65 \%$ of homicides from 2000 to $2008 .^{[15]}$ Globally, much of the variance in homicide rates has been explained by changes in firearm homicide, ${ }^{[16]}$ and it is conceivable that the Western Cape fared better in terms of enforcement of firearms legislation until 2009.

According to the SAPS, the Western Cape homicide rate remained constant since the

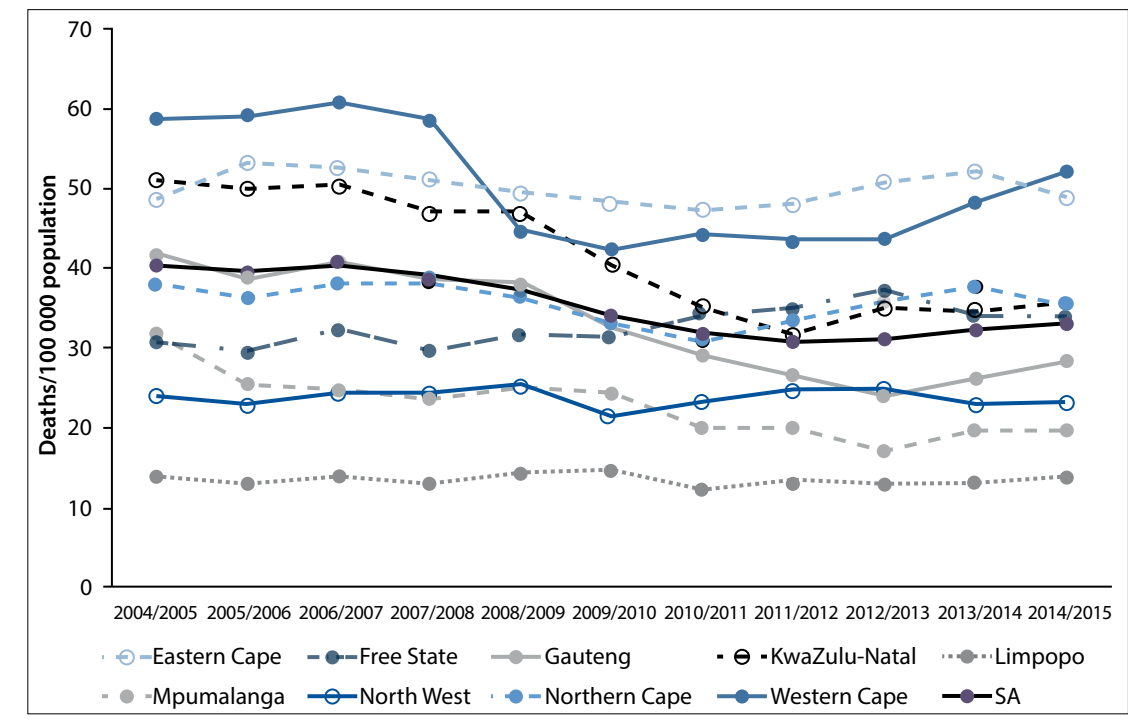

Fig. 1. SAPS crude homicide rates by province, 2004/2005 - 2014/2015. (Source: South African Police Service, $2004-2014,{ }^{[4]}$ and 2014/2015 rates from the Institute for Security Studies. ${ }^{[5]}$ )

Table 1. Age-standardised homicide rate (ASR) and crude homicide rate (CR) (/100 000) by province and area based on the Injury Mortality Survey (IMS), SA 2009 ( $N=19$ 028)

\begin{tabular}{|c|c|c|c|c|}
\hline Provincial ranking & $\begin{array}{l}\text { IMS metro ASR } \\
(95 \% \mathrm{CI})\end{array}$ & $\begin{array}{l}\text { IMS non-metro ASR } \\
(95 \% \mathrm{CI})\end{array}$ & $\begin{array}{l}\text { IMS homicide ASR } \\
(95 \% \mathrm{CI})\end{array}$ & $\begin{array}{l}\text { IMS homicide CR } \\
(95 \% \mathrm{CI})\end{array}$ \\
\hline 1. Eastern Cape & $62.2(9.4-115.5)$ & $55.4(8.4-102.8)$ & $57.9(20.9-94.9)$ & $53.5(20.2-86.8)$ \\
\hline 2. Northern Cape & * & $53.6(4.2-104.6)$ & $53.6(4.2-104.6)$ & $51.5(3.6-99.3)$ \\
\hline 3. $\mathrm{KZN}$ & $72.3(30.6-114.0)$ & $37.9(19.3-56.5)$ & $50.8(31.1-70.4)$ & $47.3(29.6-65.0)$ \\
\hline 4. Western Cape ${ }^{\dagger}$ & 41.8 & 37.0 & 40.1 & 43.0 \\
\hline 5. Gauteng & $36.2(19.2-53.2)$ & $\ddagger$ & $36.2(19.2-53.2)$ & $38.5(21.1-55.9)$ \\
\hline 6. Free State & * & $35.3(10.0-60.7)$ & $35.3(10.0-60.7)$ & $35.3(10.4-60.1)$ \\
\hline 7. North West & * & $25.1(7.6-42.5)$ & $25.1(7.6-42.5)$ & $25.0(8.0-41.9)$ \\
\hline 8. Limpopo & * & $18.8(3.8-34.1)$ & $18.8(3.8-34.1)$ & $16.8(3.7-29.9)$ \\
\hline 9. Mpumalanga & * & $17.5(4.0-31.1)$ & $17.5(4.0-31.1)$ & $16.5(4.1-28.9)$ \\
\hline South Africa & $45.1(37.3-52.9)$ & $33.2(25.0-41.4)$ & $38.4(33.6-43.3)$ & $37.9(33.6-42.3)$ \\
\hline
\end{tabular}


decline but has shown an increase in 2013/2014 and currently ranks highest. However, in this regard it is possible that certain other SAPS provincial rates are under-reported. The SAPS statistics for 2009 showed that the Northern Cape's rate for attempted murder was nearly double the rate for the Western Cape and has been highest of all the provinces from 2004 to 2011. ${ }^{[4]}$ This could be the result of statistics not being updated to homicide in the event of death, but there has been past speculation regarding findings that are particular to attempted murder rates and the fact that these are easier to manipulate than homicide statistics. ${ }^{[7,17]}$ This should be investigated. Reports of police corruption, with the most recent implicating a senior policeman for illegally supplying confiscated weapons to Cape Town gangs ${ }^{[18,19]}$ provide further impetus to the understanding that the number of firearms in circulation, and illegally obtained firearms in particular, may explain the latest increase in Western Cape homicide rates.

There are limitations in comparing the 2009 Injury Mortality Survey with the SAPS figures. Our study represented a calendar year, whereas the SAPS reports on financial years. The sampling strategy for our study was based on attaining metro/non-metro rather than provincial representivity. This explained the wide confidence intervals and possibly also the anomalous results for the Northern Cape.

The Western Cape is fortunate to have alternative data sources to monitor trends in homicides over time. A similar source of data is needed to investigate the decrease in the reported SAPS homicide rates for KZN between 2009 and 2011, given the high levels of firearm homicide reported in earlier studies and the contention surrounding the accuracy of KZN crime statistics. ${ }^{[20]}$ The latest release of the 2014/2015 SAPS crime statistics should be assessed in a similar manner, with a more recent data source, to validate its accuracy on a regular basis.

\section{References}

1. Bradshaw D, Nannan N, Laubscher R, et al. South African National Burden of Disease Study 2000: Estimates of Provincial Mortality. Cape Town: South African Medical Research Council, 2004.

2. Matzopoulos RG, Thompson ML, Myers JE. Firearm and nonfirearm homicide in 5 South African cities: A retrospective population-based study. Am J Public Health 2014;104(3):455-460. [http://dx.doi. org/10.2105/AJPH.2013.310650]

3. Leggett T. What's up in the Cape? Crime rates in Western and Northern Cape provinces. SA Crime Quarterly 2004;No.7:15-20.

4. South African Police Service. RSA: April to March 2004 - 2014: Crime Categories Figures and Ratios 2014. http://www.saps.gov.za/resource_centre/publications/statistics/crimestats/2014/crime_stats.php (accessed 27 July 2015).

5. Institute for Security Studies. Murder and robbery - overview of the official statistics: 2014/2015. Fact sheet, September 2015. https://www.issafrica.org/crimehub/uploads/SA-Crime-
(nstitute for Security Studies. Murder and robbery - overview of the official statistics: Stats\%E2\%80\%932015-Murder-and-robbery-fact-sheetV2.pdf (accessed 9 October 2015).

6. Matzopoulos R, Bhalla K, Harrison J. Homicide. In: Donnelly PD, Ward CL, eds. Oxford Textbook of Violence Prevention: Epidemiology, Evidence and Policy. Oxford: Oxford University Press, 2015:11-77. Bruce D. 'The ones in the pile were the ones going down': The reliability of violent crime statistics. SA Crime Quarterly 2010;No.31:1-17

8. Matzopoulos R, Prinsloo M, Pillay-van Wyk V, et al. Injury-related mortality in South Africa: A retrospective descriptive study of post-mortem investigations. Bull World Health Organ 2015;93:303313. [http://dx.doi.org/10.2471/BLT.14.145771]

9. Matzopoulos R, Martin LJ, Wadee S, et al. The Provincial Injury Mortality Surveillance System (PIMSS): A surveillance tool for the Western Cape. Inj Prev 2010;16(Suppl 1):A47-A48. [http://dx.doi. org/10.1136/ip.2010.029215.172]

10. Mobenzi Researcher. Mobenzi Home Page 2011. http://www.mobenzi.com/researcher (accessed 22 April 2013).

11. World Health Organization. International Statistical Classification of Diseases and Related Health Problems - Tenth Revision. Vol. 2. Geneva: WHO, 2008. http://www.who.int/classifications/apps/icd/ icd10online/ (accessed 15 November 2014)

12. Matzopoulos R, Myers JE. The Western Cape Government's new Integrated Provincial Violence Prevention Policy Framework: Successes and challenges. Aggress Violent Behav 2014;19(6):649-646. [http://dx.doi.org/10.1016/j.avb.2014.09.009]

13. Prinsloo M, ed. A Profile of Fatal Injuries in South Africa, 2005. Seventh Annual Report of the National Injury Mortality Surveillance System. Cape Town: MRC-UNISA Crime, Violence and Injury Lead Programme, 2007.

4. Matzopoulos R, Prinsloo M, Bradshaw D, et al. The Injury Mortality Survey: A National Study of Injury Mortality Levels and Causes in South Africa in 2009. Cape Town: Medical Research Council, 2013.

15. Otieno G, Marinda E, Bärnighausen T, Tanser F. High rates of homicide in a rural South African population (2000-2008): Findings from a population-based cohort study. Popul Health Metr 2015;13:20. [http://dx.doi.org/10.1186/s12963-015-0054-0]

16. Bhalla K, Matzopoulos R, Harrison J, et al. Tracking national homicide rates: Generating estimates using vital registration data. Small Arms Survey: Issue Brief No.1 2012:1-12.

using vital registration data. Small Arms Survey: Issue Brief No.1 2012:1-12.
17. Gould C, Burger J, Newham G. The SAPS crime statistics: What they tell us - and what they don't. SA Crime Quarterly 2012;No.42:3-12.
Could C, Burger J, Newham G. The

18. Baadjies M. 'Dirty cop sold us 200 guns'. Daily Voice 15 July 2015.
19. Dolley C. Police gave guns to gangs'. Weekend Argus 28 September 2014.

20. Dawood Z, Dzanibe S. New KZN crime stats show massive spikes. Daily News 25 September 2014.

Accepted 23 October 2015 